\title{
CLARICE LISPECTOR PARA MULHERES - E HOMENS - DO SÉCULO XXI
}

\author{
Maria Tereza Amodeo* \\ Andresa da Silveira ${ }^{* *}$
}

RESUMO: Conhecida por transitar pela narrativa - do romance à crônica, do conto à literatura infantil, sem falar nos artigos de jornal -, Clarice Lispector foi lida e relida em cerca de trinta idiomas e hoje se tornou popular na internet por meio de frases soltas de sua autoria ou não, mas geralmente descontextualizadas ou até transfiguradas. Acredita-se, entretanto, que as personagens femininas que a autora criou há cerca de sessenta anos, em Laços de família, ainda repercutem no século XXI. Este artigo pretende sinalizar a atualidade de seu texto e a possibilidade de renovadas leituras, por meio da análise das personagens femininas de alguns contos da obra referida. Para tanto, recuperam-se brevemente alguns aspectos da trajetória literária da autora, problematizando sua rejeição à vinculação a pautas ideológicas. Críticos literários como Regina Zilberman, Benedito Nunes, Nadia Gotlib, Yudith Rosenbaum e Benjamin Moser orientam essa reflexão. Ao relacionar as personagens de Clarice à contemporaneidade, dados de realidade em relação à posição da mulher nos dias de hoje são pontuados e analisados, tendo como apoio para as questões de gênero e feminismo contribuições de Simone de Beuavoir, Heloisa Buarque de Holanda, Marcia Tiburi e Bell Hooks. Os contos em questão constroem universos ficcionais autônomos, de forte sentido imaginativo, que permitem uma análise crítica da sociedade, promovendo o exercício da alteridade.

Palavras-chave: Contos; Laços de família; Clarice Lispector; Crítica feminista; Século XXI.

\section{Muito Prazer, Clarice Lispector}

Em tempos de posturas ideológicas tão acirradamente polarizadas como os de hoje, em que se esperam - ou até se exigem - das pessoas que assumam posições bem definidas, pode causar estranheza a afirmativa da crítica literária Regina Zilberman sobre a escritora Clarice Lispector em artigo de 1998: “Judia, mas não sionista, do sexo feminino, mas não feminista militante, escritora recatada, mas mulher vaidosa, Clarice Lispector constitui hoje

\footnotetext{
* Doutora em Linguística e Letras pela Pontifícia Universidade Católica do Rio Grande do Sul (Puc-RS). Professora titular da Puc-RS. Professora visitante da UFR Langues et Civilisations - Département des études lusophones da Université Bordeaux Montaigne, em Bordeaux, França (2018). Membro do Núcleo Docente Estruturante do Curso de Letras - Língua Portuguesa e Respectivas Literaturas, do Núcleo de Iniciação à Docência e da Comissão Científica da Escola de Humanidades da Puc-RS.

** Mestranda em Literatura pela Pontifícia Universidade Católica do Rio Grande do Sul (Puc-RS). 
um dos portos seguros da crítica e da história da literatura brasileira." (p.7). A leitura da época, que parece sugerir falta de engajamento político da autora, pode ser entendida como uma tentativa de neutralizar todo o caráter ideológico que porventura se possa associar à sua obra, em defesa do consenso entre os críticos literários acerca do seu valor estético. Entretanto, reconhecendo que a obra da autora pode encontrar eco nas "vertentes ligadas às questões de gênero e etnia", dentre outras possibilidades, Zilberman já insinua muito da potencialidade do texto clariceano.

Conhecida por transitar pela narrativa - do romance à crônica, do conto à literatura infantil, sem falar nos artigos de jornal -, Clarice Lispector foi lida e relida em cerca de trinta idiomas, desde que estreou, na década de 40, com o romance Perto do coração selvagem - muito bem acolhido pela crítica e premiado pela Academia Brasileira de Letras (ZILBERMAN, 1998). O escritor estadunidense, premiado pela biografia de Clarice, Benjamin Moser (2016), afirma que o feitiço dela "cresceu exponencialmente após sua morte”, que ocorreu prematuramente em 1977. Naquela época,

[...]teria soado como exagero afirmar que era o escritor mais importante do Brasil moderno. Hoje, quando já não parece exagero nenhum, as questões de prevalência artística são, até certo ponto, irrelevantes. O que importa é o amor magnético que inspira nos seus admiradores. Para eles, Clarice é uma das maiores experiências emocionais de suas vidas. (MOSER, 2016, p.7)

Quer seja por sua qualidade artística, amplamente reconhecida pelos críticos, quer seja pela forma como atrai/conquista seus leitores, Clarice é unanimidade; o que surpreende, entretanto, nos dias de hoje, é o fato de ter se tornado uma das figuras mais populares da Internet, mesmo tendo sido avessa à exposição pública enquanto ainda vivia. Numa rápida visada às redes sociais mais conhecidas, percebe-se que ela tem assumido o papel de "conselheira amorosa", por meio de frases veiculadas fora do contexto original ou por outras, nem sempre de sua autoria.

O fato é que o nome de Clarice Lispector, hoje, também circula entre internautas, em especial entre as mulheres, que, mesmo sem jamais terem lido um texto completo da autora, de uma forma ou de outra, são atingidos por suas palavras, embora soltas, 
descontextualizadas ou até transfiguradas. Investindo na ideia de que certas personagens femininas que Clarice criou há cerca de sessenta anos, mais especificamente nos contos de Laços de família, ainda repercutem nas mulheres do século XXI, propõe-se, neste artigo, um movimento que pretende sinalizar a atualidade deste texto e a possibilidade de renovadas leituras.

Tendo em vista que a extensão e a densidade de sua produção inviabilizam qualquer tentativa de apreendê-la e descrevê-la como uma totalidade, impõe-se "uma abordagem individual de cada uma de suas obras" (ZILBERMAN, 1998, p.11), no caso deste artigo, do livro publicado em 1960, pela análise de alguns contos. Esses, dentre os oitenta e cinco contos que Clarice escreveu hoje estão também disponíveis na antologia recentemente organizada por Benjamin Moser Todos os contos (2016), que teve sua primeira edição em inglês nos Estados Unidos e no Reino Unido em 2015, o que evidencia o interesse na produção da autora para além do Brasil e do seu tempo de produção.

\section{Clarice, potencialmente feminista}

Tendo por foco a recepção da ficção de Clarice Lispector, o crítico literário Benedito Nunes, em artigo publicado em 1998, identifica três diferentes fases:

A primeira começa com a publicação de seu livro de estreia, [...], apenas conhecido entre críticos e escritores. Porém, numa segunda fase, a partir de 1959, o livro de contos Laços de família conquistou o público universitário e despertou interesse pelos outros romances da autora, O lustre e $A$ cidade sitiada, publicados em 1946 e 1949 respectivamente, e a Maçã no escuro, em 1961.

[...] a morte da autora abriu uma terceira fase de recepção à sua obra, condicionada, depois da impressão desconcertante que produzira $A$ paixão segundo G.H., romance de 1964, às peculiaridades de dois livros, $A$ bora da estrela que precedeu de meses o passamento de Clarice Lispector em 1977, e Um sopro de vida, publicado postumamente. (p.75)

Segundo Nunes, funcionando como um efeito retroativo, a obra inteira da autora passa, então, a ser realmente compreendida, tendo em vista a experiência de introspecção, 
"na sondagem dos estados da consciência individual", que principiara no seu romance de estreia. (1998, p.75).

Passados mais de vinte anos dessa categorização trifásica da recepção do texto de Clarice, talvez hoje se possa falar de uma quarta fase, influenciada pela circulação de partes de textos de Clarice na internet? É possível, mas difícil de comprovar. Pela ampla divulgação nas mídias dos cem anos de seu nascimento? Bem provável, mas também muito arriscado afirmar. Pela recente e grandiosa publicação de Todos os contos? Tamanho empreendimento editorial, lançado antes nos países de língua inglesa, disponível em livro impresso e e-book, certamente contribuiu para a divulgação da obra da autora, mas também aponta para o interesse na sua produção, que levou à realização das edições inglesa e brasileira. $\mathrm{O}$ fato é que a leitura dos textos de Clarice Lispector pelos leitores e leitoras contemporâneos ${ }^{1}$ pode oferecer uma experiência muito qualificada, tendo em vista, principalmente, as questões relacionadas à posição da mulher na sociedade.

Conforme afirma Nadia Batella Gotlib², em depoimento à jornalista Laís Modelli, na matéria publicada no site da BBC News/Brasil (2017), o olhar de Clarice

registra os padrões de comportamento redutores de uma sociedade machista e patriarcal [...]. Não é gratuito o fato de que as personagens femininas, de repente, se encontram num outro mundo, não domesticado, selvagem, em que pode experimentar livremente a reinvenção de si mesmas.

Embora nunca tenha se declarado explicitamente uma feminista, Clarice Lispector "provavelmente não gostaria de ser lembrada assim por não aceitar classificações de sua obra", afirma Yudith Rosenbaum3 também na matéria jornalística referida anteriormente (MODELLI, 2017), estabelecendo um vínculo muito estreito entre a pessoa e a obra.

\footnotetext{
${ }^{1}$ A recente experiência localizada de leitura dos contos de Clarice que as autoras deste artigo têm oportunizado aos seus alunos de ensino básico e superior tem se revelado surpreendente. Os alunos e alunas por reiteradas vezes salientaram a atualidade da obra, "parece que escreveu hoje", alguns diziam - fato que também contribuiu para a produção deste artigo.

${ }^{2}$ Autora da obra de caráter crítico-biográfico sobre Clarice Lispector denominada Clarice: uma vida que se conta. São Paulo: Ática, 1995.

${ }^{3}$ Outra especialista em Clarice Lispector, autora de Metamorfoses do mal: uma leitura de Clarice Lispector. São Paulo: Edusp, 1999.
} 
Entretanto, o que ficou para a posteridade e, principalmente, para o(a)s leitore(a)s contemporâneo(a)s foi uma literatura que problematiza a forma como se constroem os papéis de gênero na sociedade, o que, lamentavelmente, continua sendo tema urgente nos dias de hoje.

Os contos de Laços de família foram produzidos antes de 1960 - década em que começam a se organizar os movimentos feministas. Embora Clarice não tenha se engajado a eles como militante, seus contos expressam os motivos por que o feminismo começa a se erigir numa sociedade, em que a mulher era vista apenas como gestora do lar, da maternidade, responsável por grande parte do sucesso matrimonial e representante de uma imagem frágil. Esses padrões sociais servem para definir regras de hábitos e atitudes, modos de se relacionar com as pessoas e de se vestir, dentre outros. Nessa perspectiva, é importante constatar que os padrões impostos à mulher contemplam uma construção social e não certos fatores biológicos, como afirma a pensadora e ativista do feminismo Simone de Beauvoir, na sua célebre frase:

Ninguém nasce mulher, torna-se mulher. Nenhum destino biológico, psíquico, econômico define a forma que a fêmea humana assume no seio da sociedade; é o conjunto da civilização que elabora esse produto intermediário entre macho e o castrado que qualificam o feminino. (BEAUVOIR, 1980, p. 9)

Clarice foi, principalmente a seu tempo, revolucionária, porque quebrou o padrão da época no que se refere tanto ao mercado editorial, como em relação aos estereótipos da imagem feminina que descortinou. Na obra em que reúne todos os contos de Clarice, Benjamin Moser pontua:

Clarice Lispector, como estes contos deixam claro, conheceu intimamente estas barreiras. Suas personagens lutam contra concepções ideológicas sobre o lugar da própria mulher na sociedade. Enfrentam problemas práticos com maridos e filhos. Preocupam-se com dinheiro. Confrontam-se com o desespero que desemboca em bebida, na loucura ou no suicídio. Tal como outras escritoras, Clarice não teve aceitação fácil dos editores. (2016, p. 11)

Apesar da posição social privilegiada de mulher branca, de classe média, casada com um diplomata e com trabalhadoras domésticas em sua casa que a auxiliavam na vida 
doméstica e na maternidade, Clarice passou por juventude difícil. De origem judaica e vinda de um país marcado pela fome e pela guerra racial como a Ucrânia desse período, aprendeu, desde cedo, as dores das perdas, como afirma Moser:

Como é que Clarice Lispector - logo ela - conseguiu triunfar? Ela vinha de uma tradição de fracasso, de uma tradição de falta de tradição, como escritora brasileira, como escritora, como mulher, mas talvez principalmente em consequência de suas origens. Seus primeiros anos de vida foram tão catastróficos que é um milagre que haja conseguido sobreviver. (MOSER, 1960, p. 17).

A partir disso, talvez seja possível afirmar que a criação literária da autora tenha recebido influências do seu passado caótico e presente opressor, na medida em que as suas personagens são mulheres em conflito com a própria identidade e com a posição que ocupam na sociedade. Além disso, sua vivência como imigrante pode ter favorecido certo desprendimento moral para escrever sobre problemas enraizados na cultura brasileira da época, ainda que de maneira menos explícita, como sugere Moser: "Ser estrangeira por outro lado, isentou-a de fazer as coisas do modo habitual. Foi uma alienação cultural produtiva, e a outra face da alienação é a liberdade” (MOSER, 2006, p.19).

Lembrando o crítico literário Antonio Candido (1980), para quem é impossível dissociar a obra literária do seu impacto social, cabem recuperar as considerações da também crítica literária Heloísa Buarque de Holanda, em sua obra Explosão feminista (2018), onde afirma que o feminismo é uma questão social.

Na década de 60, o movimento estava no início da segunda onda, fase crucial para a sua consolidação política, visto que uma série de estudos teóricos sobre as condições de vida das mulheres se intensificavam, como, por exemplo, a obra O segundo sexo, de Simone de Beauvoir, que havia sido publicada dez anos antes, porém estava recém estabelecendo notoriedade e adquirindo traduções em outros países.

Além de $O$ segundo sexo, também estava ocorrendo uma grande discussão acerca da obra Mística feminina e do ativismo de Beth Friedman, assim como $A$ dialética do sexo, de Shulamith Firestone. Essas teorias, dentre outras, pautaram as discussões da segunda onda, que se caracterizou como uma fase de luta por direitos reprodutivos e discussões a respeito 
da sexualidade (HOLANDA, 2018). Assim, as feministas desse contexto foram as primeiras a apontar que, apesar de todas as diferenças entre as mulheres do mundo, ainda havia algo que unia a todas: a opressão com base no sexo.

As transformações sociais ocorridas em outros países, como, por exemplo, na Inglaterra e nos Estados Unidos, despertaram nas mulheres não apenas a ambição de conquistar o seu espaço acadêmico e profissional, mas também fez emergir uma consciência política feminina. Os homens sempre dominaram âmbitos intelectuais e para as mulheres restavam apenas os papéis de filhas, esposas e mães.

No Brasil, no entanto, as discussões feministas recém estavam ganhando espaço e se situavam em um momento distinto de outros países, conforme afirma Heloísa Buarque de Holanda:

Como muitas mulheres da década de 1960 que participaram dos movimentos estudantis, da UNE, dos $\mathrm{CPCS}^{2}$ e da cultura de oposição à ditadura, militei em várias frentes, mas, inicialmente, não me identifiquei diretamente com as lutas feministas, que surgiam na Europa e nos Estados Unidos levantando a bandeira "o pessoal é político" e defendendo o direito ao corpo, ao aborto, à liberdade sexual e ao fim das desigualdades no trabalho e no contexto familiar. No Brasil, a coisa foi diferente. A maioria dessas bandeiras confrontavam, diretamente, vários dogmas da Igreja, uma das principais instituições progressistas na época. (2018, p. 13)

Essas novas concepções motivaram as brasileiras a pensarem mais na ideia de controle dos métodos anticoncepcionais, na liberdade individual e sexual, na maneira de vestirse e comportar-se, na igualdade de direitos entre os gêneros, porém de forma secundária e mostrando mais preocupações com outras questões.

O resultado foi uma fragilização inicial do nosso feminismo, que mostrava certo recuo em relação ao feminismo internacional, concentrando-se, prioritariamente, nas questões trabalhistas, na demanda por creches, no controle da violência doméstica e no enfrentamento das desigualdades sociais entre homens e mulheres ao longo da década de 1970. (HOLANDA, 2018, p. 14).

E foi nesse contexto que Clarice Lispector publicou Laços de família que denunciam, de forma subjetiva, as abnegações que as personagens escolhem - ou são induzidas a escolher - passar em suas vidas, tornando as narrativas bem próximas da realidade social. O 
termo subjetivo, nessa perspectiva, se refere às características mais marcantes e encantadoras dos textos de Clarice: parecem uma superfície rasa, mas à medida que se adentra nas histórias surgem diversas camadas de sentido e de profundidade. Nesse sentido que se ousa afirmar que Clarice sempre foi feminista. A despeito de sua rejeição a rótulos, sua obra extrapola a pessoa para viver nos seus leitores e nas suas leitoras, para além do seu tempo.

\section{As mulheres de Clarice}

A qualificada, variada e expressiva fortuna crítica sobre a obra de Clarice Lispector realmente oferece perspectivas muito ricas para os estudiosos. A proposta de revisitar alguns dos contos de Laços de família focaliza como as personagens femininas constituem-se literariamente, dando conta de mimetizar a discussão acerca da posição da mulher na sociedade, que ainda encontra eco nos dias de hoje.

A personagem central do conto "Devaneio e Embriaguez duma Rapariga" é mulher de classe média, mãe, casada, que busca refúgio na embriaguez para suportar sua vida doméstica: "E aquela vaidade de estar embriagada a facilitar-lhe um tal desdenho por tudo, a torná-la madura e redonda como uma grande vaca." (1993, p. 13). Ao mesmo tempo em que se mostra infeliz, também se culpa, a todo momento, por sentir-se de tal modo, demonstrando viver um conflito interior - "ai, que vagabunda que me saíste, censurou-se curiosa e satisfeita" (p. 12).

O narrador onisciente relata, além dos acontecimentos, os pensamentos da rapariga, que evidenciam um certo desdém em relação ao contexto no qual está inserida, através de uma linguagem carregada de ironia e repleta de denúncias sutis. A personagem demonstra desinteresse pelo marido e pelas supostas funções do lar atribuídas a ela como mulher: "Só acordou com o marido a voltar do trabalho e a entrar pelo quarto adentro. Não quis jantar e nem sair dos seus cuidados, dormiu de novo: o homem lá que se regalasse com as sobras do almoço" (p. 10). Além disso, menciona que não ama o marido e deseja encontrar o amor em outro, futuramente: "Ela ainda à cama, tranquila, improvisada. Ela amava... Estava previamente a amar o homem que um dia ela ia amar" (p. 11). 
Os momentos de embriaguez funcionam como escape da condição de submissão ao casamento e aos afazeres domésticos, mas ela tem outra preocupação, geralmente associada ao plano psicológico da mulher, como forma de manter a tradição: a opinião da própria mãe. A todo momento menciona a mãe como figura feminina de maior importância em sua vida, parece lhe dever satisfações. A mãe é o modelo a lhe lembrar como deve ser: "Ai que infeliz que sou, minha mãe" (p. 14), assim como: "Ai que cousa se me dá! Pensou desesperada. Teria comido demais? Ai que cousa se me dá, minha santa mãe!” (p. 18).

A personagem parece sufocada naquele universo familiar que a cerca. Quando aprecia um quadro exposto num restaurante, pensa: “[...] mas que sensibilidade! quando olhava o quadro tão bem pintado do restaurante ficava logo com sensibilidade artística. Ninguém lhe tiraria cá das ideias que nascera mesmo para outras cousas. Ela sempre fora pelas obras d'arte" (p. 14). Ao "entrar" no quadro, sai da sua rotina e tem certeza de que existe um mundo lá fora para ser vivido.

O conto Amor, também constituído de um narrador onisciente, relata um dia vivido pela personagem Ana, que é mãe, esposa e aparentemente vive uma rotina sem conflitos. É uma mulher conduzida pelos afazeres domésticos, que cuida de todos, menos de si mesma "Ana dava a tudo, tranquilamente, sua mão pequena e forte, sua corrente de vida" (p.29). Quando não havia mais ocupação com os cuidados da casa, dos filhos e do marido, o vazio existencial a acometia: "Quando nada mais precisava de sua força, inquietava-se." (p.30).

Em certo episódio, Ana vai até o mercado para fazer compras e cozinhar o jantar, mas, ao entrar no bonde, ele anda com velocidade e, de repente, os ovos que carregava caem e quebram-se. A seguir, a personagem passa a observar um homem cego na rua que está mascando chicletes "Ele mastigava gomas na escuridão" (p.34). Observar a face e a mastigação do homem cego a faz perder-se em seus pensamentos e deixar de descer no lugar correto. Como um momento de epifania, Ana desencadeia uma série de questionamentos, que causam o começo de uma crise - ou iluminação - existencial: "O mal estava feito. Por quê? Teria esquecido de que havia cegos? A piedade a sufocava, Ana respirava 
pesadamente. Mesmo as coisas que existiam antes estavam de sobreaviso, tinham um ar hostil. O mundo se tornara de novo um mal-estar.” (p.33).

Então, ao descer no Jardim Botânico e adentrar o parque sem propósito, Ana demonstra estar em busca de respostas ou talvez de uma fuga habitual de si mesma. Quando senta em um banco e começa a observar a natureza em sua volta, passa a fazer comparações das plantas e dos animais com a vida, que agora não parece mais ser tão simples como a sua rotina. Talvez, a grande ironia seja que um deficiente visual a tenha tirado da própria escuridão. Ana fica dividida entre o fascínio e o nojo. E, conduzida pelas suas reflexões, lembra-se, de súbito, que a sua família a esperava. Assim, volta para casa rapidamente, porém sem esquecer o que sentiu durante a tarde. Quando Ana regressa para a sua casa, surge uma sensação íntima de deslocamento e um estranhamento por parte do leitor, como se a personalidade da personagem tivesse se tornado incompatível com as pessoas e as paredes do espaço.

Diante disso, cria-se a expectativa de que Ana pode se desacomodar e seguir o desejo de explorar a vida conforme a sua vontade, em um mundo cheio de crueldade, mas também de boas possibilidades. No entanto, durante o jantar com a família, Ana volta a se conformar com a realidade e, mesmo sem esquecer a experiência do dia, vai recuperando, aos poucos, a sensação de segurança e de conforto com o marido e os filhos. Além disso, a culpa de um possível afastamento dos filhos também a perturba:

Abraçou o filho quase a ponto de machucá-lo. Como se soubesse de um mal - o cego ou o belo Jardim Botânico? - agarrava-se a ele, a quem queria acima de tudo. Fora atingida pelo demônio da fé. A vida é horrível, disse-lhe baixo, faminta. O que faria se seguisse o chamado do cego? (LISPECTOR, 1993, p.38)

As expressões da personagem que encerram o conto exemplificam o modo como Ana parece voltar a se afundar na alienação de antes: "penteava-se agora diante do espelho, por um instante sem nenhum mundo no coração" (p.41). Assim, a personagem demonstra o amor por todos, menos por si mesma ou pela busca de uma identidade. Há o temor do 
juízo de valor do outro, mas também o de ser excluída pelas pessoas com quem se importa, ou pior ainda, excluída pela sociedade.

O conto Feliz. Aniversário narra o aniversário de 89 da matriarca de uma família de classe média. Embora suas falas sejam muito reduzidas ao longo de toda a narrativa, ela é a protagonista, pois tudo e todos estão ali em função dela, a aniversariante.

A habilidade de Clarice em tecer a narrativa tornou este um dos seus contos mais conhecidos. A descrição minuciosa dos detalhes do espaço, dos gestos, ações, comportamentos, pensamentos e falas da família contrastam com o quase total silêncio da senhora. Essa dissonância se materializa na hora de cantar "o parabéns": uns cantam em português, outros em inglês. A reação da senhora é o cuspe no chão, que evidencia que ela percebe toda a hipocrisia daquela comemoração. É a forma que ela usa par mostrar seu repúdio pela família, que decidira seu destino há anos ao determinar que a filha Zilda, "a única mulher entre os seis irmãos homens" (p.72) ficaria encarregada de alojar e cuidar da mãe tarefa destinada à filha mulher.

Após o episódio do cuspe, a aniversariante pede um copo de vinho e, interpelada pela neta que a chama de "vovozinha", responde: "Que vovozinha que nada!" "Que o diabo vos carregue, corja de maricas, cornos e vagabundas! me dá um copo de vinho, Dorothy!" (p. 80). Estabelece-se um constrangimento geral, por meio de uma atmosfera de tensão que anuncia uma discussão que não acontece.

A raiva da senhora traduz uma vida inteira de obediência voluntária. Como mulher, sempre esteve sujeita à sua condição de filha, esposa e mãe; cumpriu submissa o papel que lhe fora incumbido: "Ela, a forte, que casara em hora e tempo devidos com um bom homem a quem, obediente e independente, ela respeitara; a quem respeitara e que lhe fizera filhos e lhe pagara os partos e lhe honrara os resguardos.” (p.78). Dessa forma, Clarice consegue, neste conto, projetar a velhice da mulher subjugada à lógica machista e opressora, que impõe padrões e papéis que se perpetuam ao longo da vida, dos tempos.

O conto Laços de família reúne todos os temas que estão espraiados no livro. A mulher em relação ao homem, à própria mãe, aos filhos e os conflitos relacionados à sua identidade no âmbito da família ocupam a narrativa. A relação entre Severina e Catarina, 
mãe e filha, respectivamente, é a base da narrativa A vista da mãe, que passa alguns dias na casa da filha, constitui o enredo que se organiza a partir do momento em que as duas se dirigem à Estação, quando se encerra a visita. Entretanto, o período da visita é retomado e as experiências da duas durante esse tempo remete à relação que se construiu ao longo da vida e deixou marcas definitivas em Catarina.

Apesar de as duas não privarem de qualquer intimidade, quando chegam à Estação e Severina já está dentro do trem, Catarina parece se recordar da idade já avançada da mãe e é tomada por uma ternura igualmente distorcida: "Ninguém mais pode te amar senão eu, pensou a mulher rindo pelos olhos; e o peso da responsabilidade deu-lhe à boca um gosto de sangue. Como se "mãe e filha" fossem vida e repugnância. Não, não podia dizer que amava sua mãe. Sua mãe lhe doía, era isso" (p.120).

Nesse contínuo movimento de introspecção que Catarina vive, ela percebe a necessidade de reconhecimento da relação entre as duas, de validação dos sentimentos: "Que coisa tinham esquecido de dizer uma a outra e agora era tarde demais. Parecia-lhe que deveriam um dia ter dito assim: sou tua mãe, Catarina. E ela deveria ter respondido: e eu sou tua filha." (p. 121). Entretanto, só se falam em códigos de uma língua secreta criada para dizer o não dito, deixando implícito o afeto não expressado.

O diálogo com o filho, que tem lugar assim que volta para casa, quando a chama de mãe, faz Catarina perceber-se nesse reconhecimento. Ela puxa o menino pela mão, permitindo-se essa intimidade, essa demonstração física de afeto e sai com ele para passear, sem dar qualquer para o marido que fica atônito com a atitude da mulher que a deixa sozinho num sábado, "porque o sábado era seu, mas queria que sua mulher e seu filho estivessem em casa[...].” (p. 124).

A focalização se volta, então, para o marido, que vê a estrutura familiar construída até então abalada. Catarina está diferente. Catarina não quer repetir com o próprio filho a relação de indiferença que tem com a mãe. Para isso, precisa romper com a estrutura familiar construída e sedimentada. Pelo menos ela tenta.

Interessante que justamente este conto dê título ao livro, uma narrativa em que a personagem feminina tem uma revelação e reage contra o modelo que a formara. Se não 
foi a intenção da autora ou da editora (o que é bem duvidável), esse é um entendimento possível, uma interpretação livre: há saída para as mulheres nesse universo machista e opressor.

Outras tantas narrativas do livro têm mulheres como protagonistas: quer seja a jovem que se torna mulher em "Preciosidade", a Pequena Flor em a "Menor Mulher do Mundo", ou a mulher infeliz no amor de "O Búfalo". É fato que todas as mulheres de Clarice em Laços de família permitem leituras além de seu tempo. Inseridas em narrativas habilmente construídas, falam também às mulheres de hoje - e não só a elas -, que ainda se veem enredadas em estruturas que se constituíram ao longo dos tempos, a despeito dos avanços já conquistados.

\section{Clarice para as mulheres do século XXI?}

As mulheres do século XXI são conscientes de suas prerrogativas, conquistaram a denominação de "empoderadas", porque sabem dos seus direitos e das suas capacidades. Entretanto, a simples observação da realidade evidencia que ainda há muito por que lutar. As estruturas sociais, embora pareçam reformuladas, ainda deixam entrever atitudes e procedimentos alinhados aos velhos e tradicionais papéis destinados às mulheres no passado.

Mais do que observar o entorno empiricamente, a interessante pesquisa qualitativa realizada na área de Psicologia Clínica e Cultura ${ }^{4}$, apresentada no artigo "Donas de casa: classes diferentes, experiências desiguais", aponta resultados muito interessantes para esta reflexão. Recolhendo depoimentos de três mulheres donas de casas de classes sociais diferentes, que, ao tempo da pesquisa, vão "na contramão do novo modelo feminino" (SANTOS e DINIZ, 2011, p.137), as pesquisadoras concluem que, embora cada uma delas signifique seu trabalho dentro de casa de forma diferente, independente das classes sociais,

\footnotetext{
${ }^{4}$ A pesquisa é resultado do trabalho de mestrado de Luciana da Silva Santos, divulgado em artigo da Revista Psicologia clínica, em parceria com Gláucia Ribeiro Starling Diniz, Coordenadora do Programa de Pós-graduação em Psicologia Clínica e Cultura da Universidade de Brasília.
} 
as participantes revelaram adesão a uma identidade tradicional de gênero, apresentando discursos que atrelam o homem ao espaço público - como provedor financeiro da família - e a mulher à responsabilidade pela família e pelo cuidado do lar e dos filhos. Dentro desses papéis tradicionais da mulher, o mais profundo e unanimemente colocado foi a maternidade. (p.147)

Naturalmente trata-se de uma pesquisa pontual, cujo corpus se restringe a três pessoas apenas e qualquer generalização pode ser considerada temerária. Contudo, ela evidencia que ainda existem mulheres que reproduzem o modelo tradicional de divisão do trabalho, que atribui ao homem a responsabilidade de ser o provedor, e à mulher a tarefa de organizar a casa e cuidar da educação dos filhos.

Uma outra pesquisa da Havard Business School, publicada na Harvard business review (2016), realizada junto a 25.000 ex-alunos, em sua maioria graduados no MBA, com idades entre 26 e 47 anos, revelou que $\mathbf{6 0 \%}$ dos homens (a maioria casados) sentiam-se “extremamente satisfeitos" com suas carreiras; em contrapartida, somente $40 \%$ das mulheres diziam o mesmo. E o resultado mais surpreendente da pesquisa foi a revelação de são os maridos e não os filhos os responsáveis por impedir o crescimento profissional das mulheres.

Porque os maridos exigem mais ou menos sutilmente ou por opção de algumas mulheres, identifica-se, nos últimos tempos, uma onda conservadora que tem levado muitas mulheres com formação acadêmica a optarem por se dedicar aos filhos, abandonando suas profissões. Por outro lado, há mulheres, em especial nas classes menos favorecidas, que são o arrimo da família: provêm seus filhos, educam e muitas vezes são abandonadas pelos maridos. A vida lhes parece um desafio constante e imaginar-se dona de casa, sustentada pelo seu homem, pode até ser um sonho para algumas.

A filósofa Marcia Tiburi afirma que a mulher conquistou o seu espaço no mercado de trabalho, porém com uma falsa igualdade de gênero:

Enquanto isso, mulheres são convencidas, por meio de uma combinação perversa entre violência e sedução, que a família e o amor valem mais do que tudo, quando, na verdade, o amor de devoção à família serve para amenizar a escravização, que, desmontada, faria bem a todos, menos àqueles que realmente preferem uma sociedade 
injusta porque se valem covardemente de seus privilégios. (TIBURI, 2018, p.19)

A literatura, com sua capacidade de construir universos ficcionais autônomos, de forte sentido imaginativo e, por isso, convincentes, críveis, constitui-se também como possibilidade de análise crítica da sociedade, promovendo o exercício da alteridade. Não se trata de compreender a literatura como uma forma de elixir para curar os males da sociedade, mas de promover o deslocamento do leitor da realidade imediata para a ficcional, estimulando um olhar crítico para o mundo circundante, possível pelo trabalho criativo da palavra literária. Leitores e leitoras contemporâneos, lamentavelmente, percebem-se nas narrativas de Clarice. Nesse sentido a teórica feminista estadunidense Bell Hooks afirma:

[...]todos nós, mulheres e homens, temos sido socializados desde o nascimento para aceitar pensamentos sexistas, Como consequência, mulheres podem ser tão sexistas quanto homens. [...] Para acabar com o patriarcado (outra maneira de nomear o sexismo institucionalizado), precisamos deixar claro que todos nós participamos da disseminação do sexismo até mudarmos a consciência e o coração; até desapegarmos de pensamentos e ações sexistas e substituí-los por pensamento e ações feministas. (HOOKS, 2018, p.13)

Conforme a escritora Bell Hooks afirma, "o feminismo é para todo mundo”, tendo em vista que a cultura sexista afeta toda a humanidade. Ademais, apesar de a mulher ter adquirido conquistas importantes, ainda há muitas barreiras a serem quebradas e um longo caminho para a igualdade de gênero ser atingida.

Através da leitura e pesquisa dos contos citados, foi possível observar personagens, que passam por conflitos internos ao se depararem com as suas figuras femininas e os seus projetos de vida. Além disso, também foi viável identificar denúncias da condição subalterna em que as mulheres vivem.

As obras de Clarice Lispector têm promovido estudos importantes, em especial relacionados ao ponto de vista psicológico, sendo muito frequentemente deslocadas das questões sociais. No entanto, suas narrativas constituem-se em universos habilmente construídos pelo arranjo e força da palavra literária, que permitem indagações existenciais e sociais de variada ordem, em especial, como se pretendeu analisar, as que questionam os grupos sociais que sustentam separações por classe e sexo. Naturalmente não se esgotam 
aqui os debates relacionados à questão de gênero e da crítica literária feminista na obra de Clarice Lispector.

\title{
CLARICE LISPECTOR FOR WOMEN - AND MEN - OF THE 21 ${ }^{\text {ST }}$ CENTURY
}

\begin{abstract}
Known for moving through the narrative - from the novel to the chronicle, from the short story to children's literature, not to mention newspaper articles - Clarice Lispector was read and reread in about thirty languages and today has become popular on the Internet through phrases that belong to her or not, but usually discontextualized or even transfigured. It is believed, however, that the women characters the author created about sixty years ago, in Laços de familia, still have repercussions in the $21^{\text {st }}$ Century. This article intends to signal the actuality of her text and the possibility of renewed readings, through the analysis of the women characters of some tales of the aforementioned work. To this end, some aspects of the author's literary trajectory are briefly recovered, problematizing her rejection of attachment to ideological agendas. Literary critics such as Regina Zilberman, Benedito Nunes, Nadia Gotlib, Yudith Rosenbaum and Benjamin Moser guide this reflection. By relating Clarice's characters to contemporaneity, reality data regarding women's position nowadays are punctuated and analyzed, having as support for gender and feminism issues contributions from Simone de Beuavoir, Heloisa Buarque de Holanda, Marcia Tiburi and Bell Hooks. The tales in question build autonomous fictional universes, with a strong imaginative sense, which allow a critical analysis of society, promoting the exercise of otherness.
\end{abstract}

KEYWORDS: Short stories; Laços de família; Clarice Lispector; Feminist criticism; $21^{\text {st }}$ Century.

\section{REFERÊNCIAS}

BEAUVOIR, Simone de. O segundo sexo. Rio de Janeiro: Editora Nova Fronteira, 2008.

CANDIDO, Antonio. Literatura e sociedade. Rio de Janeiro: Ouro Sobre Azul, 2006.

HOLANDA, Heloísa Buarque de. Explosão feminista. São Paulo: Companhia das Letras, 2018.

HOOKS, Bell. O feminismo épara todo mundo. São Paulo: Editora Record, 2018.

LISPECTOR, Clarice. Laços de família. Rio de Janeiro: Francisco Alves, 1993.

MOSER, Benjamin. Todos os contos. Rio de Janeiro: Editora Rocco, 2015.

TIBURI, Marcia. Feminismo em comum: para todas, todes e todos. Rio de janeiro: Rosa dos tempos, 2018.

MODELLI, Laís. Clarice Lispector: mais de 40 anos após morte, escritora desperta mais questões do que quando viva. BBC News/Brasil. 2017. Disponível em: https:/ /www. bbc.com/portuguese/geral-42313869 
NUNES, Benedito. Os destroços da introspecção. In: ZILBERMAN, Regina et al. Clarice Lispector: a narração do indizível. Porto Alegre: Artes e Ofícios, EDIPUC, Instituto Cultural Judaico Marc Chagal, 1998.

SANTOS, Luciana da Silva e DINIZ, Gláucia Ribeiro Starling. Donas de casa: classes diferentes, experiências desiguais. Psicologia Clínica. Rio de Janeiro, v. 23 n. 2, p.137-149, 2011. Disponível em: https://www.scielo.br/pdf/pc/v23n2/09v23n2.pdf Acesso em: 28 set 2020 .

HARVARD BUSINESS SCHOOL. Life \& Leadership after Hbs. A Preview of findings. From Harvard Business School's Alumni Survey on the experiences of its alumni across career, family, and life paths. April, 2013. Disponível em: https://www.hbs.edu/women50/images/women_survey_preview_130402.pdf. Acesso em: 27 set 2020.

ZILBERMAN, Regina. A estrela e seus críticos. In: ZILBERMAN, Regina et al. Clarice Lispector: a narração do indizível. Porto Alegre: Artes e Ofícios, EDIPUC, Instituto Cultural Judaico Marc Chagal, 1998.

Recebido em: 30/09/2020.

Aprovado em: 30/12/2020. 